\title{
(D) The effect of miniscrew length and bone density on anchorage resistance: An in vitro study
}

\author{
I. Gusti Aju Wahju Ardani, Rachman Indharmawan, Thalca Hamid
}

Available online: 3 July 2019

Keywords

Bone density

Miniscrew length

Stability
Mots clés

Densité osseuse

Longueur des mini-vis Stabilité
Orthodontic Department, Faculty of Dental Medicine, Campus A Universitas

Airlangga Jl, Prof. Dr. Moestopo No. 47, 60132 Surabaya, East Java, Indonesia.

Correspondence:

I Gusti Aju Wahju Ardani, Orthodontic Department, Faculty of Dental Medicine,

Campus A Universitas Airlangga Jl, Prof. Dr. Moestopo No. 47, 60132 Surabaya, East

Java, Indonesia.

wahju_ardani@fkg.unair.ac.id

\section{Summary}

Introduction > With conventional anchorage, it is usually hard to accomplish a satisfactory result with an absolute anchorage, and this limitation could be resolved by the usage of mini-screw. The successful rate of miniscrew usage depends on its stability, which was determined by its length, bone density, cortical bone thickness, the insertion technique, the insertion angle, and the applied loads.

objective > To observe the effect of miniscrew length and bone density on anchorage resistance. Material and methods > Thirty pieces of miniscrew with $1.6 \mathrm{~mm}$ in diameter were divided into three groups based on its length $(n=10): 10 \mathrm{~mm}(\mathrm{~L}), 8 \mathrm{~mm}(\mathrm{M})$, and $6 \mathrm{~mm}(\mathrm{~S})$. Each group was further divided into 2 sub-groups: to be planted in optimal density bovine ribs (L1, M1, S1) and to be planted in low-density bovine ribs ( $L 2, M 2, S 2)$. The density of bovine ribs was measured by CBCT. After the insertion of miniscrews based on respective groups, tensile test was done by means of Autograf Univerval Testing Machine to measure its stability. The data recorded was analysed using the Least Significant Difference (LSD) Fisher's test.

Results > The results of this study showed that L1 provided the greatest stability than other groups. On the other hand, the least stability was found in S2.

Conclusion > The length of miniscrew and the density of bone affect the stability of miniscrew. In bone with optimum density, $10 \mathrm{~mm}$ and $8 \mathrm{~mm}$ miniscrew equipped good anchorage resistance while in bone with low-density only $10 \mathrm{~mm}$ miniscrew provided favourable anchorage resistance.

\section{Résumé}

Effets de la longueur des mini-vis et de la densité osseuse sur la résistance d'ancrage : une étude in vitro

Introduction > Il est en pratique difficile d'obtenir un ancrage absolu satisfaisant avec un ancrage conventionnel et cet obstacle pourrait être surmonté en utilisant des mini-vis. Le taux de réussite de I'utilisation d'une mini-vis dépend de sa stabilité qui a été déterminée par sa longueur, la 
densité osseuse, l'épaisseur de l'os cortical, la technique d'insertion, l'angle d'insertion et les charges appliquées.

objectif > Observer l'effet de la longueur des mini-vis et de la densité osseuse sur la résistance de l'ancrage.

Matériels et méthodes > Trente mini-vis de 1,6 $\mathrm{mm}$ de diamètre ont été divisées en trois groupes selon leur longueur $(\mathrm{n}=10): 10 \mathrm{~mm}(\mathrm{~L}), 8 \mathrm{~mm}(\mathrm{M})$ et $6 \mathrm{~mm}(\mathrm{~S})$. Chaque groupe a été divisé en deux sous-groupes : les mini-vis à implanter dans des côtes bovines de densité optimale (L1, M1, S1) et les mini-vis à implanter dans des côtes bovines de faible densité (L2, M2, S2). La densité des côtes bovines a été mesurée au moyen de tomodensitométrie CBCT. Une fois les mini-vis insérées en fonction des groupes respectifs, elles ont été testées en traction pour mesurer leur stabilité par une machine d'essai Universal Autograf. Les données enregistrées ont été analysées à l'aide du test post hoc de différence significative minimale (LSD) de Fisher.

Résultats > Les résultats de cette étude ont montré que $L 1$ offrait une plus grande stabilité que les autres groupes. En revanche, c'est avec S2 que la stabilité était la plus faible.

Conclusion > La longueur de la mini-vis et la densité osseuse affectent la stabilité de la mini-vis. Dans les os à densité optimale, les mini-vis de $10 \mathrm{~mm}$ et $8 \mathrm{~mm}$ ont une bonne résistance d'ancrage, alors que dans les os à faible densité, seule une mini-vis de $10 \mathrm{~mm}$ offre une résistance d'ancrage fovorable.

\section{Introduction}

In orthodontic tooth movement, anchorage is required to prevent undesirable tooth movement in order to achieve a successful treatment, thus control of anchorage is essential during orthodontic treatment [1]. Conventional anchorage could be classified as extra-oral anchorage, which could be done by using headgear or facemask, and intra oral anchorage, which could be done with transpalatal arch, Nance, or lingual arch. Unfortunately, a satisfactory anchorage result is difficult to be achieved by conventional anchorage as it has a limitation, which could be overcome by the usage of miniscrew [2].

Miniscrew usage could accomplish various orthodontic tooth movement, such as anterior and posterior intrusion, molar distalisation, and en-masse retraction or protraction, which previously infeasible with conventional anchorage [3]. It also could safely produce a successful space closure after extraction and intrude overerupted maxillary and mandibular incisive, without affecting posterior teeth and the vertical dimension [4].

Miniscrew stability determined by the insertion technique, the insertion angle, its length, the applied loads, bone density, and cortical bone thickness [5]. Previous study done by Petrey et al. [6] stated that there is a correlation between miniscrew length and its loading ability in producing primary stability, which is essential in order to be able to receive load in absolute anchorage. The length of anchorage extends its surface contact with cortical bone, which is optimizing its stability while the orthodontic force is given. In opposition to the statement, other studies conducted by Kuroda et al. [7] argued that there is no correlation between miniscrew length and its stability. An increase on miniscrew length could cause alveolar bone damage and resulting in its mobility [8].
In addition, bone density is one of the factors influencing mini screw insertion failure besides the presence of bone inflammation in miniscrew location insertion, the age and the characteristic of bone. Therefore, bone density is an important factor to be considered in determining the successful of orthodontic treatment [9].

The difference in research findings of mini-screw length correlation with its stability encouraged a further experiment to determine the effect of miniscrew length and bone density on anchorage resistance.

\section{Material and methods Experimental design}

All experimental procedures were approved by the Board for Animal Experiments, Faculty of Dental Medicine, Universitas Airlangga, No. 030/HRECC.FODM/III/2017. The experimental research involved post-test only control group design using four fresh ribs bovine. To determine bone density, each bovine was scanned by Cone Beam Computed Tomography (CBCT) unit (Orthopantomograph OP300, Wisconsin, USA). The result of bone density measurement was presented in $\mathrm{HU}$ (hounsfield units). The optimum density range of bone was 500-850 HU, while it was considered low density if less than $500 \mathrm{HU}$. After the measurement, the samples immersed in $\mathrm{PZ}$ solution $(\mathrm{NaCl}$ $0,9 \%$ ) for $1 \times 24$ hours and stored in room temperature prior the treatment.

Thirty self-drilling orthodontic miniscrews (diameter $1.6 \mathrm{~mm}$; Biokey, Taoyuan, Taiwan) were divided into three groups based on its length $(n=10): 10 \mathrm{~mm}(\mathrm{~L}), 8 \mathrm{~mm}(\mathrm{M})$, and $6 \mathrm{~mm}(\mathrm{~S})$. Each group was further divided into 2 sub-groups: to be inserted in optimal density bovine ribs ( $L 1, M 1, S 1)$ and to be inserted in 


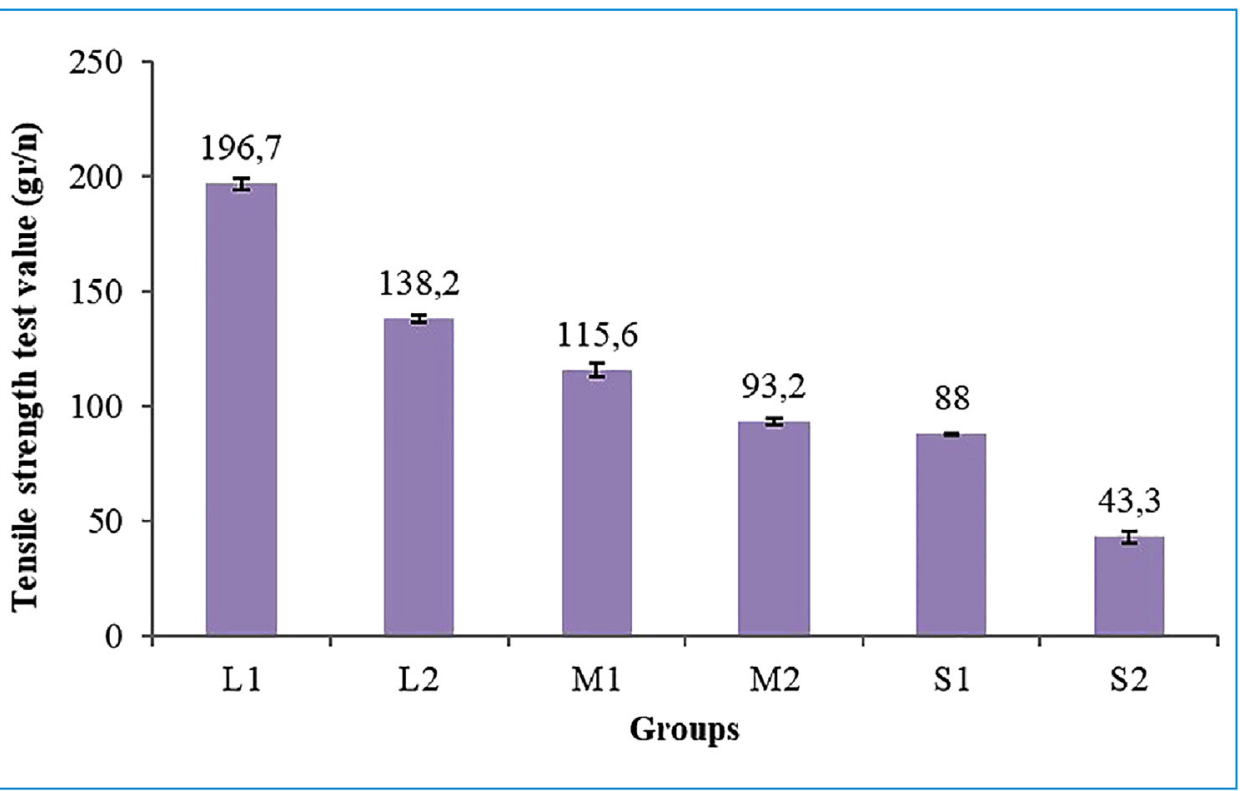

FIGURE 1

Bar graph of the tensile strength test mean value of $1.6 \mathrm{~mm}$ in diameter miniscrew insertion in the low and optimum bone densities low-density bovine ribs ( $L 2, M 2, S 2)$. The placement of all miniscrews was done by a single operator using screwdriver ( $3 \mathrm{M}$, St. Paul, USA) according to the manufacturer with $45^{\circ}$ of insertion angle. All samples with miniscrew inserted were bonded with ligature wire (RMO, Colorado, USA) in order to be able to be held with autograf. Tensile strength test was done perpendicularly to miniscrew insertion angle by means of Universal Testing Machine jenis Autograf (Shimadzu E10, Kyoto, Japan) until the miniscrew was pulled out. The value of required force to pull out the miniscrew was recorded and then analysed to determine the most stable miniscrew based in its length.

\section{Statistical analysis}

All data were tested for normal distribution by means of Kolmogorov-Smirnov test. One Way ANOVA and Least Significant Difference (LSD) test $(P>0.05)$ were performed to determine the influence of different miniscrew length and bone density to the stability of miniscrew using statistical software program SPPS version 20 (IBM, New York, USA).

\section{Results}

Bone density measurement was done to four different cow ribs prior the treatment and the result was: A bovine ribs age$\mathrm{d}<$ one-year old has 298.5 hounsfield units (HU) in bone density, B bovine ribs aged < one-year old has $320.8 \mathrm{HU}$, C bovine ribs aged $1.5-2$ years old has $592.5 \mathrm{HU}$, and the $\mathrm{D}$ bovine ribs aged $1.5-2$ years old has $785.7 \mathrm{HU}$. A and B bovine ribs were considered having an optimum bone density, while $C$ and $D$ bovine ribs were considered having a low bone density.
LSD test used for the tensile strength test data was done to find the difference of miniscrew stability between $6 \mathrm{~mm}, 8 \mathrm{~mm}$, and $10 \mathrm{~mm}$ in length to the optimal bone density of bovine ribs (L1, $M 1, S 1)$ and low-density bovine ribs (L2, M2, S2) (figure 1). The results confirmed that there is a significant difference between each group $(P=0.00<0.05)$. L1 group has the highest tensile strength result $(196.7 \mathrm{~g} / \mathrm{n})$, while the lowest strength was found in $S 2$ group $(43.3 \mathrm{~g} / \mathrm{n})$.

\section{Discussion}

Bone density is one of the possible factors to cause the failure of miniscrew placement besides the presence of bone inflammation in the location of miniscrew insertion, the characteristic and age of the skeletal. Therefore, bone density is one of the key factors to determine the success of orthodontic treatment [9]. Mandible has a statistically higher density value in basal cortical bone compared to alveolar bone. The result of this study showed that the thickness and the density of bone vary with the distance from alveolar crest in the interradicular area. The success of miniscrew as an orthodontic anchorage could be achieved if it was placed in an area with $6 \mathrm{~mm}$ bone density from apical to the alveolar crest [10].

In general, there is a progressive increase of bone density from anterior area with lower bone density to posterior area with higher bone density in mandible. Several studies found that there was a higher bone density in cortical area compared to the cancellous area. Therefore, it is necessary for miniscrew to be inserted in an oblique angle to the long axis of the tooth in order to obtain a boarder surface contact between miniscrew and cortical bone [11]. 
Alveolar bone density test could be done using cone beam computed tomography (CBCT) radiograph photography. Alveolar bone density values of the posterior of mandible and anterior of maxilla are 500-850 HU, while those of the anterior of mandible and the posterior of maxilla are less than 0-500 HU and more than $850 \mathrm{HU}$ [12].

Bovine ribs were used as the insertion media of the miniscrew and prior bone density measurement was done. This measurement was done to prove that bovine ribs have a similar density with human mandible bone, which showed a similar characteristic with the presence of cortical and cancellous bone [13]. This study used bovine ribs with different age as mature bovine aged 1.5-2 years old has higher density compared to bovine aged less than a year old [14]. The result showed that the low bone density ribs have the value of $320.8 \mathrm{HU}$ and $298.5 \mathrm{HU}$, while the optimum bone density ribs have the values of $692.5 \mathrm{HU}$ and $785.7 \mathrm{HU}$. This was in accordance with a study conducted by Lagravère [12], which stated that alveolar bone density values range was $500-850 \mathrm{HU}$ and low bone density value was less than $500 \mathrm{HU}$.

The result of tensile strength test was used to observe the required force value to pull out the mini-screw in order to find the most stable miniscrew based on its length. The higher the required force, the stable the miniscrew is. The tensile strength test of miniscrew in low bone density showed that $10 \mathrm{~mm}$ miniscrew required the highest force with $138.2 \mathrm{~g} / \mathrm{n}$ compared to $8 \mathrm{~mm}$ and $6 \mathrm{~mm}$ miniscrew, which consecutively were 93.2 and $43.3 \mathrm{~g} / \mathrm{n}$. Besides, the result of tensile strength test in optimum bone density showed that $10 \mathrm{~mm}$ mini-screw required $196.70 \mathrm{~g} / \mathrm{n}$, while $8 \mathrm{~mm}$ and $6 \mathrm{~mm}$ required 115.64 and $87.99 \mathrm{~g} / \mathrm{n}$, respectively. It showed a significant difference of the required force resulted from different miniscrew lengths and bone densities, which was in accordance with several studies. A study conducted by Petrey et al. [6] confirmed that miniscrew length has an effect to its stability in alveolar bone by increasing the contact surface area with cortical bone and resulted in a better stability when orthodontic force was given.

Sarul et al. [15] also stated that the length of miniscrew might be an important factor that determine the long-term success rate in the mandible of 20- to 29-year-old women, which was showed by a higher stability found in 8-mm miniscrew that in $6 \mathrm{~mm}$ miniscrew. Moreover, study conducted by Nienkemper et al. [16] proved that $11 \mathrm{~mm}$ miniscrew provide greater stability than $9 \mathrm{~mm}$ miniscrew when inserted in the midpalatal region and Chatzigianni et al. [13] reported that $9 \mathrm{~mm}$ miniscrew displaced significantly less than $7 \mathrm{~mm}$ miniscrew when a high force loaded. The bigger diameter and the longer miniscrew will gain greater stability and lower level of stress and displacement [17].
On the other hand, Cheng et al. [18] and Park et al. [19] reported that the length of miniscrews had no effect on implant survival and their clinical success.

Anterior en mass retraction in orthodontic movement required $115-140 \mathrm{~g} / \mathrm{n}$ of force value $[5,20]$. Based on the mean of required value, $8 \mathrm{~mm}$ and $10 \mathrm{~mm}$ miniscrew in optimum bone density have the most optimum value for en mass movement, while in low bone density, $10 \mathrm{~mm}$ mini-screw has the most optimum value.

The longer the miniscrew, the broader its contact surface with the cortical bone and generally its increased stability. Histomorphometrical and biomechanical analysis could prove that miniscrew length affects its stability. The length of miniscrew determines the stability as it was retained to some cortical boned and the ratio of cortical bone to cancellous bone was known to have an important role to the stability of miniscrew. Axial force resulted could increase the retention of miniscrew with bone osseointegration [5]. Miniscrew length affects the primary stability. With adequate primary stability (without any movement of the implant), bone will stimulate the remodelling process around the implant [21]. Excellent miniscrew stability is necessary while en masse teeth retraction is done. By replacing the $6 \mathrm{~mm}$ mini-screw with the $10 \mathrm{~mm}$ will increase the surface contact between cortical bone and miniscrew. Miniscrew with $10 \mathrm{~mm}$ in length, which inserted in $45^{\circ}$-insertion degree, will increase the surface contact by 1.5 -fold [22].

The placement of miniscrew with $8-10 \mathrm{~mm}$ will increase the surface contact and improve the mechanic retention of miniscrew to the cortical bone [23]. By inserting the $10 \mathrm{~mm}$ miniscrew with $10-45^{\circ}$ insertion angles to cortical bone, it will prevent the destruction of tooth apex in the interradicular area. This insertion angle will minimise the contact with tooth apex as appropriate space is relatively available, the contact surface between miniscrew and cortical bone will increase, and the stability will improve [24]. Insertion of $10 \mathrm{~mm}$ miniscrew will improve its stability and increase the clinical accuracy, as the part of miniscrew implanted in cortical bone is wider [25].

\section{Conclusion}

The length of mini-screw and the density of bone affect the stability of miniscrew. In bone with optimum density, $10 \mathrm{~mm}$ and $8 \mathrm{~mm}$ miniscrew equipped good anchorage resistance while in bone with low-density only $10 \mathrm{~mm}$ mini-screw provided favourable anchorage resistance.

Disclosure of interest: the authors declare that they have no competing interest. 


\section{References}

[1] Proffit WR, Fields HW, Sarver DM. Contemporary orthodontic. 5th ed. Missouri: Mosby; 2012p. 278-304.

[2] Trevisi H, Zanelato RT. State of art orthodontics: self ligating appliances, miniscrews and second molar extraction. 1st ed. New York: Mosby; 2011p. 76-153.

[3] Smith AL. An in-vitro study evaluating the fracture resistance and insertion torque of self drilling mini implants upon insertion into synthetic high density mandibular bone [Thesis]. the University of Western Ontario; 2013.

[4] Kaku M, Kojima S, Sumi H, et al. Gummy smile and facial profile correction using miniscrew anchorage. Angle Orthod 2012:82:170-7.

[5] Xu Z, Wu Y, Zhao L, et al. Effect of placement angle on stability of loaded titanium miniscrew in beagle jaws. Angle Orthod 2013;83:659-66.

[6] Petrey JS, Saunders MM, Kluemper GT, Cunningham LL, Beeman CS. Temporary anchorage device insertion variables: effect on retention. Angle Orthod 2010;80:446-53.

[7] Kuroda S, Sugawara Y, Deguchi T, Kyung HM, Takano-Yamamoto T. Clinical use of miniscrew implants as orthodontic anchorage: success rates and postoperative discomfort. Am J Orthod Dentofacial Orthop 2007;131:9-15.

[8] Pickard MB, Dechow P, Rossouw PE, Buschang PH. Effect of miniscrew orientation on implant stability and resistance to failure. Am J Orthod Dentofacial Orthop 2010;137 (1):91-9.

[9] Watanabe H, Deguchi T, Hasegawa M, Ito M, Kim S, Takano-Yamamoto T. Orthodontic miniscrew failure rate and root proximity, insertion angle, bone contact length, and bone density. Orthod Craniofac Res 2013;16:44-55.
[10] Cassetta M, Sofan AAA, Altieri F, Barbato E. Evaluation of alveolar cortical bone thickness and density for orthodontic mini-implat placement. J Clin Exp Dent 2013;5(5):e245-52.

[11] Borges MS, Muncha JN. Bone density assessment for mini-implants position. Dental Press J Orthod 2010;15:e1-9.

[12] Lagravère $M$, Low $C$, Flores-Mir $C$, et al. Intraexaminer and interexaminer reliabilities of landmark identification on digitized lateral cephalograms and formatted 3-dimensional cone-beam computerized tomography images. Am J Orthod Dentofacial Orthop 2010;137:598-604.

[13] Chatzigianni A, Keilig L, Reimann S, Eliades T, Bourauel C. Effect of mini-implant length and diameter on primary stability under loading with two force levels. Eur J Orthod 2011;33:381-7.

[14] Hastuti D. Tingkat keberhasilan inseminasi buatan sapi potong ditinjau dari angka konsepsi dan service per conception. Mediagro 2007;4:12-20.

[15] Sarul M, Minch L, Park HS, AntoszewskaSmith J. Effect of the length of orthodontic mini-screw implants on their long-term stability: a prospective study. Angle Orthod 2015;85:33-8.

[16] Nienkemper M, Wilmes B, Pauls A, Drescher D. Impact of mini-implant length on stability at the initial healing period: a controlled clinical study. Head Face Med 2013;9:30-7.

[17] Jiang L, Kong L, Li T, Gu Z, Hou R, Duan Y. Optimal selections of orthodontic miniimplant diameter and length by biomechanical consideration: a three-dimensional finite element analysis. Adv Eng Softw 2009;40: 1124-1130.
[18] Cheng S], Tseng IY, Lee IJ, Kok SH. A prospective study of the risk factors associated with failure of mini-implants used for orthodontic anchorage. Int J Oral Maxillofac Implants 2004;19:100-6.

[19] Park HS, Jeong SH, Kwon OW. Factors affecting the clinical success of screw implants used as orthodontic anchorage. Am J Orthod Dentofacial Orthop 2006;130 (1):18-25.

[20] Wilmes B, Drescher D. Impact of bone quality, implant type, and implatation site reparation on insertion torques of mini-implats used for orthodontic anchorage. Int J Oral Maxillofac Surg 2011;40(7):697-703.

[21] Shah AH. Effect of mini screw characteristics (length and outer diameter) and bone properties (cortical thickness and density) on insertion torque and pullout strength [Thesis] Saint Louis University; 2011.

[22] Deguchi T, Nasu M, Murakami K, Yabuuchi T, Kamioka H, Takano-Yamamoto T. Quantitative evaluation of cortical bone thickness with computed tpmographic scanning for orthodontic implant. Am J Orthod Dentofacia Orthop 2006;129(6):e7-12.

[23] Suzuki EY, Buranastidporn B. An adjustable surgical guide for miniscrew placement. J Clin Orthod 2005;39(10):588-90.

[24] Uzuner FD, Aslan BI. Miniscrew application in orthodontics. London: IntechOpen; 2015p. 211-37.

[25] Raji SH, Noorollahian S, Niknam SM. The effect of insertion angle on orthodontic miniscrew torque. Dent Res | 2014;11(4):448-51. 